\title{
Prevalence and Psychological Impact of Acne Vulgaris in Female Undergraduate Medical Students of Rawalpindi and Islamabad, Pakistan
}

\author{
Osama Babar $^{1}$, Amen Mobeen ${ }^{1}$ \\ 1. Dermatology, Islamic International Medical College (Riphah International University), Rawalpindi, PAK
}

Corresponding author: Osama Babar, osamababar123@gmail.com

\section{Abstract}

\section{Background:}

Acne vulgaris is a common skin disease, affecting approximately $9.4 \%$ of the world's population, with considerable effect on the quality of life. According to a previously conducted study, the prevalence rate of acne in Pakistan was found to be 5\%. And to this date, no reliable data is available about the prevalence of acne in Rawalpindi and Islamabad, Pakistan.

\section{Objectives}

To determine the prevalence of acne vulgaris and its psycho-social impact on female undergraduate medical students of Rawalpindi and Islamabad.

\section{Methods}

A cross-sectional study was conducted during the month of August 2019 among female undergraduate medical students from three randomly selected medical colleges of Rawalpindi and Islamabad. The diagnosed cases of acne vulgaris were assessed by using the Dermatology Life Quality Index (DLQI). The collected data were then analyzed using SPSS version 20 (IBM Corp., Armonk, NY, US).

\section{Results}

The prevalence of acne vulgaris was found to be $14.47 \%$ in female undergraduate medical students of Rawalpindi and Islamabad. Sixty percent $(n=99)$ were found to have itchy sores and stinging skin, $66.7 \%$ $(n=110)$ were embarrassed by their acne-prone skin, and the social activity of $60 \%(n=99)$ of the participants was affected by their active acne. Of the students, $73.9 \%$ were not affected by their acne while studying or working. Around $61.2 \%(n=101)$ complained that their acne treatment was a problem and hiding it took time or made a mess.

Received 08/30/2019 Review began 09/07/2019 Review ended 09/19/2019 Published 09/22/2019

๑) Copyright 2019 Babar et al. This is an open access article distributed under the terms of the Creative Commons Attribution License CC-BY 3.0., which permits unrestricted use, distribution, and reproduction in any medium, provided the original author and source are credited.
Two percent showed a severe impact, with $14 \%$ having very large, $44 \%$ moderate, $30 \%$ low, and the remaining $10 \%$ with no effect of acne in their psychosocial functioning.

\section{Conclusion}

Acne vulgaris is a chronic skin disease that considerably affects the psychosocial functioning of female undergraduate medical students. A holistic approach in treating acne requires the participation of a dermatologist and mental health professional.

Categories: Dermatology, Psychology, Epidemiology/Public Health

Keywords: acne in pakistan, acne vulgaris, psychological impact, dermatology life quality index (dlqi), female medical undergraduate students, prevalence, rawalpindi/islamabad

\section{Introduction}

Acne vulgaris is a chronic dermatological disease characterized by inflammatory changes in the pilosebaceous glands of the skin resulting in the formation of comedones, pustules, papules, nodules, and cysts. It is commonly associated with the bacterium Cutibacterium acnes (formerly Propionibacterium acnes ) [1].

The Global Burden of Disease project has estimated the prevalence of acne to be $9.4 \%$, ranking it as the eighth most prevalent disease worldwide. The project found a prevalence of around 5\% in Pakistan [2]. The frequency of acne vulgaris has been reported in many studies but there is a lack of data regarding the prevalence of the disease and its psychosocial impact in adolescents and young adults. On comparing both genders, it was found to have a greater psychosocial impact on females [3-5]. 
Acne vulgaris is the most common type of acne and carries a significant burden of disease. It may cause severe discomfort, permanent facial scarring, emotional and physical distress, occupational consequences, and potential psychiatric disturbances like depressive disorders and suicidal tendencies [2]. It has also been found to have a negative influence on people who intend to participate in sports [6].

The measurement of the quality of life of acne sufferers has been acknowledged as being of pivotal value in the assessment and management of the disease [7]. Previously conducted studies have found immense improvement in the symptoms and aforementioned disturbances after the treatment of the disease [8].

Acne and its impact have been well-researched and studied in various parts of the world, including the USA, Europe, and Korea. However, data from South East Asian countries like Pakistan remains scanty [4]. Moreover, there is very limited data on adolescents and adults [1].

\section{Materials And Methods \\ Research design}

A cross-sectional study was conducted during the month of August 2019, among female undergraduate medical students from three randomly selected medical institutes of Rawalpindi and Islamabad.

\section{Sample size and data collection}

Only female medical students were considered for this respective study. Out of a total of 1140 female students, 165 were diagnosed cases of acne. The medical students were assumed to be aware of acne because of the extensive teaching of dermatology in their curriculum. The diagnosed cases were further assessed by the Dermatology Life Quality Index (DLQI). The absent students were excluded from this study.

Before the data collection, it was announced that the students will be surveyed and were explained the vitality of the research. The confidentiality of the participants was also ensured.

The diagnosed participants were then asked to fill out the Dermatology Life Quality Index (DLQI) to evaluate the psychosocial impact that acne had on their lives over the past two weeks. The English version of the DLQI was chosen. The questionnaire comprises 10 questions about acne symptoms, related feelings and influence in daily and social activities, type of clothing, playing sports, job and education, in interpersonal and sexual relationships and treatment. Every question has four options and each option on the DLQI is given a particular score. "Very much" (score three), "a lot" (score two), "a little" (score one), and both "not at all" and "not relevant" are scored zero. Each individually filled DLQI score was totaled and a final score was given. A high total score was an indicator of the poor quality of life of the participant due to the disease. The effect of the disease was divided into different groups according to the total score: (0-1) without any effect, (2-5) low effect, (6-10) moderate effect, (11-20) high effect, and (21-30) severe effect [9].

\section{Ethical considerations}

Ethical approval for this study was obtained from the Ethics Review Committee of Islamic International Medical College trust. All the participants from the three medical institutes were oriented on the topic of the study. Verbal consent was taken from everyone who filled out the DLQI. Furthermore, it was also mentioned in the DLQI that the personal information of all the participants would be kept highly confidential.

\section{Statistical analysis}

Data for this study were analyzed by using the SPSS Statistics version 20 (IBM Corp., Armonk, NY, USA).

\section{Results}

A sample size of 216 students was calculated using the EpiData Software (Centers for Disease Control and Prevention, Georgia, US), which included diagnosed cases of acne along with acne-free students.

Our sample size was 1140 students from which 216 were diagnosed cases of acne vulgaris and 924 were disease-free. A prevalence rate of $14.47 \%(n=216)$ was calculated from this data. Out of the 216 questionnaires filled out, only 165 were analyzed to determine the psychosocial impact of the disease, giving a response rate of $76.389 \%$. This was due to the incomplete submission of questionnaires.

A total of $60 \%(\mathrm{n}=99)$ participants complained of itchy sores and painful stinging skin with $3 \%(\mathrm{n}=5)$ very much, $16.4 \%(n=27)$ a lot, $40.6 \%(n=67)$ a little, and $40 \%(n=66)$ not at all. Sixty-six point seven percent $(n=110)$ were embarrassed and self-conscious because of their acne-prone skin, with $7.9 \%(n=13)$ very much, $32.7 \%(n=54)$ a lot, $26.1 \%(n=43)$ a little, and 33.3\% $(n=55)$ not at all. More than half $(53.3 \%, n=55)$ of the participants were not worried about acne while shopping. Approximately half $(50.3 \%, n=83)$ of the participants reported that their clothes were not influenced by their skin. The social and leisure activities of $60 \%(n=99)$ participants were affected by their acne with $9.7 \%(n=16)$ very much, $14.5 \%(n=24)$ a lot, $35.8 \%$ 


\section{Cureus}

$(n=59)$ a little, and $40 \%(n=66)$ not at all. A majority of the participants $67.3 \%(n=111)$ were not affected by their acne in playing sports. Moreover, $73.9 \%(\mathrm{n}=122)$ participants were not affected by acne while studying and working and more than half $(58.8 \%, \mathrm{n}=97)$ of them did not have their acne influence their relationships with their partners and close friends. Eighty-four point eight $(n=140)$ did not have any sexual difficulties due to their acne while $7.9 \%(n=13)$ had little, $6 \%(n=10)$ a lot, and $1.2 \%(n=2)$ had very many difficulties. Around $61.2 \%(n=101)$ complained that their acne treatment and masking was a problem and took time or made a mess, with $38.2 \%(n=63)$ a little, $10.3 \%(n=17)$ a lot, $12.7 \%(n=21)$ very much, and $38.8 \%(n=64)$ not at all. (Table 1).

Table 1: Descriptive Analysis of the Dermatology Life Quality Index (DLQI) of Female Students with Acne

\begin{abstract}
Itchy, sore and painful/stinging skin
\end{abstract}
Embarrassed or self-conscious

Skin interfered during shopping, looking after home or garden

Skin influenced the clothes

Skin affected social or leisure activities

Skin made it difficult to play sports

Skin prevented from working or studying

Skin created problems with partner or friends

Not at all/ Not relevant
A little
A lot
Very Much

\section{Not at all/ Not relevant}

A little

A lot

Very Much

Not at all/ Not relevant

A little

A lot

Not at all/ Not relevant

A little

A lot

Very Much

4

Not at all/ Not relevant

A little

A lot

Very Much

Not at all/ Not relevant

A little

A lot

Very Much

Not at all/ Not relevant

A little

A lot

3

Very Much

Not at all/ Not relevant

A little 


\section{Cureus}

Skin caused sexual difficulties

Not at all/ Not relevant

A little

A lot

Skin treatment was a problem e.g taking time or making a mess

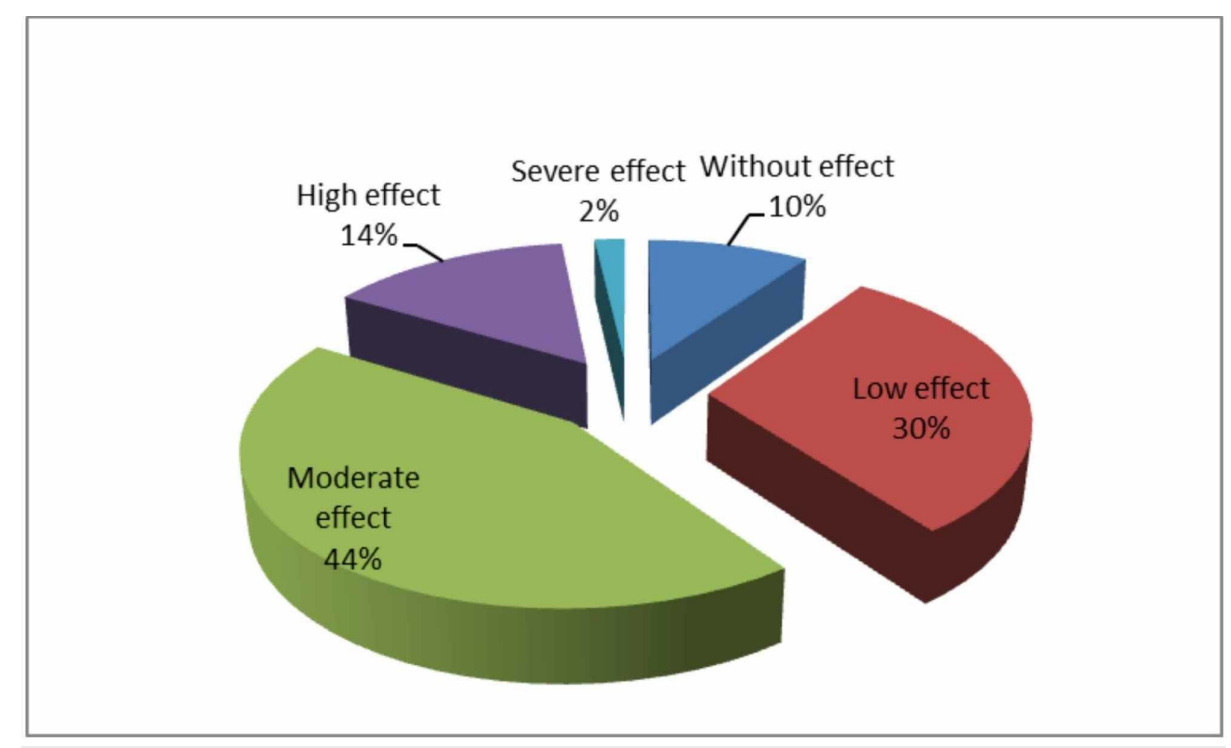

\section{FIGURE 1: Effect of acne on the psycho-social functioning of female undergraduate medical students of Rawalpindi and Islamabad.}

\section{Discussion}

Acne is a chronic inflammatory disease, and its prevalence varies in adolescents and adults among different countries and ethnic groups. Around $9.4 \%$ of the world's population suffers from acne, making it the eighthmost prevalent disease worldwide [2].

In the US, acne is seen in $85 \%$ of teenagers [10]. An overall prevalence of $60.7 \%$ was seen among adolescents of Turkey [11]. In Malaysia, a study conducted among medical students reported a prevalence of $68.1 \%$ [12]. Whereas another community-based study carried out in China reported an acne prevalence of $38 \%$ among females aged 15-19 years [13]. A research carried out in Saudi Arabia found an overall prevalence of 14.3\% among female secondary school students [14]. Most of these studies have been conducted in secondary school or high school students, with very few conducted in college and university students $[4,12,15]$. Our study focused on finding the prevalence of acne in female medical college students.

Sixty percent of the cases from this study reported having physical symptoms due to acne in the form of itchy sores or burning and stinging skin. According to Tasoula et al., $22.8 \%$ of the cases who had facial acne and $31.5 \%$ of those with back acne suffered from itchiness [16]. In another study by Reich et al., about 50\% of the cases reported itchiness as a physical symptom [17]. However, the exact nature of each physical 
manifestation was beyond the scope of this study.

Sixty-six point seven percent of the cases reported feeling embarrassed or self-conscious because of their acne. These results were consistent with another study [16]. A study by Ogedegbe found that $43.7 \%$ of the patients actually felt frustrated and embarrassed because of their acne papules and nodules [7]. In the Magin et al. study about the psychological sequelae of acne vulgaris, it was found that acne vulgaris has a negative influence on the overall self-esteem and image of the sufferers [18].

Forty-six point seven percent of the females reported that their acne interfered in their daily activities like shopping and looking after their homes. In a 2016 study by Hazarika and Archana, about $69 \%$ of the patients agreed to having faced problems in their routine activities because of their acne. A link was established between frustration, anger, and acne. It is, therefore, deducible that problems in their daily activities due to acne maybe because of evasive behavior, annoyance, and anger [6].

It has been well-established that one's appearance is often acknowledged through their clothing, making it an integral part of social acceptance [19]. Forty-nine point seven percent of the patients reported that acne influenced their choice of clothing. In the 2014 study by Ogedegbe and Henshaw, 14.4\% of adolescents avoided wearing clothes that revealed their extra facial acne [5].

It was found that the social life and leisure activities of $60 \%$ of the females were affected by acne, and they avoided going out to public places and interacting in community-based events during acne flare-ups. Yolaç et al. have also reported that social withdrawal and anxiety are major sequelae of acne among female patients [20]. Another study by Magin et al. reported avoidant behavior in many of the subjects, ultimately leading to the development of avoidant personality traits [18].

In a study, Tasoula et al. found that $14.4 \%$ of the patients reported having problems in their sports activities because of their acne [16]. We found that $32.7 \%$ of the female participants found difficulties of various degrees in sports and related activities due to their acne.

The work and studies of $26.1 \%$ of the females in this study were affected by their acne. These results were consistent with another recent study conducted in 2018 where most of the subjects reported that acne did not have a significant influence on their work or studies. However, some subjects felt that their attention on work was diverted during acute acne flare-ups, and a couple of students even had to take a day off from school because of their acne while adults reportedly had to make excuses from work during times when their acne would be at its worse [21].

We found that the relationships of $41.2 \%$ of the female students were affected by their acne. According to Magin et al., the media's portrayal of people with flawless skin has led to a false perception among its audience, leading them to believe that acne is unsanitary and contagious and clear skin is essential. This has contributed to acne patients feeling a lack of desirability [18].

Many females believe that their physical appearance has an immense influence on getting jobs and sexual partners [5]. We found that $15.2 \%$ of our patients had difficulties with their sexual partners while $2 \%$ found severe difficulty. Most participants marked the question as not relevant, possibly because they were unmarried and sexual relations outside marriage in Pakistan are a religious and criminal offense. A further, detailed analysis was beyond the scope of this study. It was found similarly low in another research having to do with the fact that most women found it embarrassing to answer questions regarding their sexual activities [22].

People suffering from acne usually buy over-the-counter acne medications before visiting a certified dermatologist [16]. Makeup application and camouflaging techniques to hide acne have led to gratification and improved quality of life for many females [23]. Subjects, however, had to spend a long time every day in order to hide their lesions and scar marks. Complaints of acne being time-consuming and skin treatment being messy were consistent with $61.2 \%$ of the females.

In $90 \%$ of the participants in this study, acne affected their psychosocial functioning to varying degrees, with $2 \%$ severely affected and $14 \%$ highly affected. A large percentage, however, remained moderately affected, amounting to $44 \%$, while $30 \%$ had low and $10 \%$ no effect on their psychosocial functioning.

\section{Limitations}

The study was conducted with female undergraduate medical students and further research needs to be done on male students and the overall prevalence as well. The data collected relied on self-reported information and depended on its subjects for authenticity. The study based its results on previously diagnosed cases of acne, assuming their knowledge and awareness of the disease due to dermatology-dedicated modules in their course of study, which may have led to a slight underestimation of the prevalence due to undetected cases, however unlikely. 
A detailed analysis of the psychosocial management and its effects on improving dysfunction due to acne was beyond the scope of this research and needs further investigation.

\section{Conclusions}

The prevalence rate of acne vulgaris is $14.47 \%$ in female undergraduate medical students of Rawalpindi and Islamabad, Pakistan. It has a significant impact on their psychosocial functioning, amounting to $90 \%$, with a variable degree of dysfunction. It causes feelings of embarrassment, difficulties in studies and work, disruption in daily social activities, and impairment of interpersonal relationships, along with its physical symptoms. Since acne is not just a disease of the skin and causes significant psychosocial impairment, treating skin lesions alone isn't sufficient. DLQI is a good tool and should be used by dermatologists and general practitioners in evaluating the patients. Psychiatrists, psychologists, and other mental health professionals should be included in the treatment plan for acne in treating psychosocial dysfunction if warranted by the DLQI.

Doctors need to be educated on the psychosocial implications of acne, and schools and colleges should have support groups and ease of access to mental health professionals for students with diseases like acne that are likely to lead to psychosocial distress and impaired functioning.

\section{Additional Information \\ Disclosures}

Human subjects: Consent was obtained by all participants in this study. Institutional Review Committee, Islamic International Medical College issued approval Riphah/IIMC/IRC/19/0341. The committee recommends that the proposal may be commenced with immediate effect as proposed. Animal subjects: All authors have confirmed that this study did not involve animal subjects or tissue. Conflicts of interest: In compliance with the ICMJE uniform disclosure form, all authors declare the following: Payment/services info: All authors have declared that no financial support was received from any organization for the submitted work. Financial relationships: All authors have declared that they have no financial relationships at present or within the previous three years with any organizations that might have an interest in the submitted work. Other relationships: All authors have declared that there are no other relationships or activities that could appear to have influenced the submitted work.

\section{References}

1. Safizadeh H, Shamsi-Meymandy S, Naeimi A: Quality of life in Iranian patients with acne . Dermatol Res Pract. 2012, 2012:571516. 10.1155/2012/571516

2. Tan J, Bhate K: A global perspective on the epidemiology of acne . Br J Dermatol. 2015, 172:3-12. 10.1111/bjd.13462

3. Yang YC, Tu HP, Hong CH, et al.: Female gender and acne disease are jointly and independently associated with the risk of major depression and suicide: a national population-based study. Biomed Res Int. 2014, 2014:504279. 10.1155/2014/504279

4. Shahzad N, Nasir J, Ikram U, Asmaa-ul-Haque, Qadir AM, Sohail MA: Frequency and psychosocial impact of acne on university and college students. J Coll Physicians Surg Pak. 2011, 21:442-443.

5. Pruthi GK, Babu N: Physical and psychosocial impact of acne in adult females . Indian J Dermatol. 2012, 57:26-29. 10.4103/0019-5154.92672

6. Hazarika N, Archana M: The psychosocial impact of acne vulgaris . Indian J Dermatol. 2016, 61:515-520. 10.4103/0019-5154.190102

7. Ogedegbe EE, Henshaw EB: Severity and impact of acne vulgaris on the quality of life of adolescents in Nigeria. Clin Cosmet Investig Dermatol. 2014, 7:329-334. 10.2147/CCID.S73302

8. Fakour Y, Noormohammadpour P, Ameri H, Ehsani AH, Mokhtari L, Khosrovanmehr N, Hoseini Nezhad SZ: The effect of isotretinoin (roaccutane) therapy on depression and quality of life of patients with severe acne . Iran J Psychiatry. 2014, 9:237-240.

9. Dermatology Quality of Life Index, English version . (2019). Accessed: August 5, 2019: http://sites.cardiff.ac.uk/dermatology.

10. Bhate K, Williams HC: Epidemiology of acne vulgaris. Br J Dermatol. 2013, 168:474-485. 10.1111/bjd.12149

11. Aksu AE, Metintas S, Saracoglu ZN, Gurel G, Sabuncu I, Arikan I, Kalyoncu C: Acne: prevalence and relationship with dietary habits in Eskisehir, Turkey. J Eur Acad Dermatol Venereol. 2012, 26:1503-1509. 10.1111/j.1468-3083.2011.04329.x

12. Muthupalaniappen L, Tan HC, Puah JW, Apipi M, Sohaimi AE, Mahat NF, Rafee NM: Acne prevalence, severity and risk factors among medical students in Malaysia. Clin Ter. 2014, 165:187-192.

13. Shen Y, Wang T, Zhou C, et al.: Prevalence of acne vulgaris in Chinese adolescents and adults: a communitybased study of 17,345 subjects in six cities. Acta Derm Venereol. 2012, 92:40-44. 10.2340/00015555-1164

14. Alanazi M.S, Hammad S.M, Mohamed A: Prevalence and psychological impact of acne vulgaris among female secondary school students in Arar city, Saudi Arabia. Electron Physician. 2018, 10:7224-7229. 10.19082/7224

15. Al-Shidhani A, Al-Rashdi S, Al-Habsi H, Rizvi S: Impact of acne on quality of life of students at Sultan Qaboos University. Oman Med J. 2015, 30:42-47. 10.5001/omj.2015.08

16. Tasoula E, Gregoriou S, Chalikias J, Lazarou D, Danopoulou I, Katsambas A, Rigopoulos D: The impact of acne vulgaris on quality of life and psychic health in young adolescents in Greece. Results of a population survey. An Bras Dermatol. 2012, 87:862-869. 10.1590/s0365-05962012000600007

17. Reich A, Trybucka K, Tracinska A, Samotij D, Jasiuk B, Srama M, Szepietowski JC: Acne itch: do acne patients 


\section{Cureus}

suffer from itching?. Acta Derm Venereol. 2008, 88:38-42. 10.2340/00015555-0355

18. Magin P, Adams J, Heading G, Pond D, Smith W: Psychological sequelae of acne vulgaris: results of a qualitative study. Can Fam Physician. 2006, 52:978-979.

19. Feingold A: Good-looking people are not what we think. Psychol Bull. 1992, 111:304-341.

20. Yarpuz AY, Saadet ED, Sanli HE, Ozgüven HD: Social anxiety level in acne vulgaris patients and its relationship to clinical variables. Turk Psikiyatri Derg. 2008, 19:29-37.

21. Fabbrocini G, Cacciapuoti S, Monfrecola G: A qualitative investigation of the impact of acne on healthrelated quality of life (HROL): development of a conceptual model. Dermatol Ther (Heidelb). 2018, 8:85-99. 10.1007/s13555-018-0224-7

22. Kulthanan K, Jiamton S, Kittisarapong R: Dermatology life quality index in Thai patients with acne . Siriraj Med J. 2007, 59:3-7.

23. Monfrecola G, Cacciapuoti S, Capasso C, Delfino M, Fabbrocini G: Tolerability and camouflaging effect of corrective makeup for acne: results of a clinical study of a novel face compact cream. Clin Cosmet Investig Dermatol. 2016, 9:307-313. 10.2147/CCID.S115192 